\title{
RETHINKING SINO-FRENCH DIASPORA FROM CROSS-CULTURAL POINT OF VIEW
}

Wen-Hui Changi

Assistant Professor, Department of Applied Linguistics and Language Studies, Chung Yuan Christian University, Taoyuan City, Taiwan

\begin{abstract}
:
The paper aims to re-think the similar and contrasted parts of contemporary Sino-French diaspora through the extended perspective of Chinese self-image from the methodology of comparative literature, by analyzing the Post-colonialism and Marginal Discourse to Diaspora Discourse. How these diaspora writers/artists both acknowledge and challenge the attachment/memory in a diaspora framework as their cross-cultural identities? How the identity intended to eliminate the concept of national borders? How the identity by describing the crosscultural elements to carry out the dual identities of Sino/ French?
\end{abstract}

Keywords: Chinese self-image, cross-cultural study, diaspora, memory, Sino-French identity

\section{Introduction}

The present emphasis on the "diaspora" aesthetics and experience has become a trend in the field of culture and literary study.i The experience of diaspora commonly refer to people who can't return to their home country as they are no longer insiders, however they do not belong to the country and society after immigration so they are not exactly outsiders either. ${ }^{\text {iii }}$ Such dissociation and uncertainty intensifies the subject's alienation and insecurity as well as imposes on them factual, material and spiritual trouble, which motivates and inspires artistic creation as a result. By rethinking Sino-French diaspora from cross-cultural point of view, this paper will focus on two Sino-French writer and artist: Pan Yu-liang (1895-1977) and Chow Ching-lie (1936-). Being a representative female painter in early $20^{\text {th }}$ century, the former spent rest of her life in France while kept trying to get back to her homeland no matter how difficult it was. On the other hand, as the childhood dream come true, the latest who is a pianist and writer moved to France where she

\footnotetext{
iCorrespondence: email vivianne@cycu.edu.tw

ii Ref.: Lee, Yu-cheng and Tee, Kim-Tong. Diaspora and Homeland Imagination: Essays in Literary and Cultural Studies. Taipei: Yun Chen, 2010. 23.

iii Ref.: Liou, Liang-Ya. "The Mother-Daughter Relationship in Maxine Hong Kingston's 'The Woman Warrior'". Chung Wai Literary 29:8(2001.01): 158-75.
} 
was confronted with various cultural shocks and where rose her intensive nostalgia. Pan Yuliang and Chow Ching-lie, their two different kinds of diasporic experiences map out a small picture of Sino-French diaspora during $20^{\text {th }}$ century which will help us rethinking deeply the term of diaspora from cross-cultural perspective.

Pan Yu-liang who was sold to a brothel at a young age but later gradually changed her path to an artistic one, is one of the Chinese French artists who experienced diaspora. In the early days, when Chinese society was biased and criticized her background, she left her family for France to study art. The profane viewpoints and the twisted life experience have cast an unforgettable shadow on the mind of the female artist who was born a few years after the ROC was founded. Even in exile out of her homeland, she made an effort to depict the oppressed female bodies through creating numerous figure portraits and self-portraits in order to reveal her motivation of self-identity and self-realization and turn around the border position of the marginalized females who are not accepted by society. Likewise, the Chinese French writer/pianist, Chow Ching-lie, attempts to pull the women out of the "other" frame that is traditionally being viewed. Through her recollection of the self-identity and historical memory, she wrote a long autographic novel in French Concerto du fleuve Jaune where she describes how she expected to become a pianist as a child and how she overcame all difficulties to pursue her dreams in France in the midst of a family business crisis and affection bonds; she also illustrates her life in Paris where she encountered all kinds of uneasiness and expresses her nostalgia through music. This essay firstly attempts to connect the two Chinese-French artists Chow Ching-lie and Pan Yu-liang and to draw out the issues of self-identity and diaspora in their works. Furthermore, we will try to rethink the similar and contrasted parts of contemporary Sino-French diaspora through the extended perspective of Chinese self-image from the methodology of comparative literature. How these diaspora writers/artists both acknowledge and challenge the attachment/memory in a diaspora framework as their cross-cultural identities? How the identity by describing the cross-cultural elements to carry out the dual identities of Sino/ French?

\section{Rewriting the concept of Diaspora}

According to Arnold Ages, the term "Diaspora" can be traced back to the $1^{\text {st }}$ century AD when the Jews resisted the Roman troops and their occupation of Palestine; the Jewish masses were later forced to leave their homeland in exile all over the world. ${ }^{\text {iv }}$ After the second half of the $20^{\text {th }}$ century, the meaning of "diaspora" was expanded in the midst of the waves of globalization and in 1986, Walter Connor simplified and generalized the early definition of diaspora that solely referred to the Jews and redefined it as "an ethnic group who live outside of their homeland". Different from the early definition that was based on ethnicity, in 1991, Alexander Kitroeff held that the initial literal meaning of diaspora was "a group of people dispersing towards all directions" with an emphasis on ethnic groups who migrate from their mother countries and yet still

\footnotetext{
iv Ref.: Ages, Arnold. The Diaspora Dimension. The Hague: Marinus Nijhoff, 1973.

v Ref.: Connor, Walter. "The Impact of Homelands Upon Diasporas". Modern Diasporas in International Politics. New York: St. Martins, 1986. 16-46.
} 
remotely connect with it with a sense of nostalgia. Rather than solely referring to those who are forced to flee to other countries due to the fall of their mother countries, the Chinese, Greeks and Jews that scatter around the world nowadays are examples of modern diaspora. ${ }^{\mathrm{vi}}$ In 2001, John Docker proposed a similar viewpoint. From a standpoint of the sense of belonging, he thinks that those who migrate are often marginalized in a host country as they are not born or grow up there. It is through the reminiscence of their homeland that they fill the emptiness deep down in the heart, which inversely become experiences of pain from loss and separation. ${ }^{\text {vii }}$ The scholar of politics William Safran further illustrates from the factor of affection. Shifting from the dimension of the sentiments for the homeland such as "pain" and "unbreakable ties" to that of culture, he maintains that people of diaspora must retain certain memories for their homeland and these are especially salient when reflecting in culture or religion in the host country. viii

Distinguishing her view from ethnicity and affection for the homeland, Wang Ai-Hua departs from a cross-national perspective and asserts that the discourse of diaspora needs to be released from inherent boundaries, especially when contemporary volunteer immigrants in host countries maintain a connection with the mother countries, rendering cross-field thinking. Therefore, she proposes a concept of "flowing" with Chinese Americans which is the so-called "flexible citizenship" when reflecting on identity. ${ }^{\text {ix }}$ In recent years, Kalra Virinder stresses in her book Diaspora and Hybridity that the term "immigrant" in the past is too narrow, and "people of diaspora" appears to be a better term that blends the concept of both immigrant and diaspora and that signifies double directions, the mobile nature of moving between the host country and the mother country. ${ }^{x}$ In addition, Dominique Schnapper distinguishes the definitions of diaspora based on the reasons people leave their homeland. According to her, besides the classic "diaspora" of the Jews, other diasporas may be traced back to many factors, for instance, the European colonization which in fact, involves causes such as missionary practices, desire for power, desire for risks, economic benefits, the wish to be free from misfortune, and so forth that are hard to evaluate. ${ }^{x i}$ Professor Kaching Toloyan draws together the above and concludes that he agrees to examine diaspora from a cross-cultural perspective, hence, immigrant, exile, refugee, foreign laborer and so forth are all examples of diaspora; he also concords the affection of the diasporic people for their motherland. ${ }^{x i}$ The cultural experiences and memories are involved in the creation of the uniqueness of their image. Regardless of the hardship and inner world of the marginalized or the scattered in various points of time and space, their cultural value judgment and life awareness penetrates and imprints their self-identity.

\footnotetext{
vi Ref.: Kitroeff, Alexander. The Transformation of Homeland-Diaspora Relations: the Greek Case in the $19^{\text {th }}-20^{\text {th }}$ Centuries. J.M. Fossey ed.. Proceedings of the First International Congress on the Hellenic Diaspora. Vol. 2. Amsterdam: Gieben: 233. vii Ref.: Docker, John. 1492 The Poetics of Diaspora. London: Continuum, 2001. vii-viii.

viii Ref.: Safran, William. "Deconstructing and Comparing Diasporas". Diaspora, Identity and Religion. Kokot Waltraud, Toloyan Khachig and Alfonso Carolin Ed.. NY: Routledge, 2006. 10.

ix Ref.: Ong, Aihwa. Flexible Citizenship: The Cultural Logics of Transnationality. London: Duke University, 1999.

${ }^{x}$ Ref.: Kalra, Virinder S.. Diaspora and Hybridity. CA: Sage Publications, 2005. 234.

xi Ref.: Schnapper, Dominique. "From the Nation-State to the Transnational World: on the Meaning and Usefulness of Diaspora as a Concept". Diaspora 8:3 (1999): 225-254.

xii Ref.: Toloyan, Kaching. "Rethinking Diasporas: Stateless Power in the Transnational Moment". Diaspora 5.1 (1996):3-36.
} 
Taking Pan Yu-liang as an example from the perspective of diaspora, her parents died when she was very young and she was sold to a brothel by her uncle. xiii At 18, she met the "decent, open, advanced and empathetic"xiv Pan Zan-hua who set her free and took her as a concubine. Since then, she began a new life. After graduation, she received a national scholarship and left for France to study the arts. Focusing on the expression of naked female bodies, she held exhibitions in Paris and Rome and was well-affirmed by the West. During the ten years (1928-1937) after she completed her study and returned to China, she held five solo exhibitions in Shanghai and Nanjing. As a woman, Pan Yu-liang made her way into the artistic arena and enjoyed remarkable achievements. This aroused the jealousy of her peers who spoke ill of her past experience in the brothel: "In Nanjing, male colleagues were jealous of Pan Yu-liang. Later, her exhibited works even became the cause of dissension. Her background was once again being openly criticized". ${ }^{\mathrm{x}}$ From 1937 to 1977, when she passed away, she was never able to return to China due to the World Wars, the Chinese political unrest and so forth. "She lived in France for more than 40 years but had never become a French citizen. She kept her nose clean there and did not sign any contract with galleries or art dealers, maintaining a decent life and an independent character". xvi The diasporic Pan Yu-liang spent the rest of her life in France and expressed her profound nostalgia for her homeland through painting. Thus, the type of her diaspora is close to the view of Professor Dominique Schnapper who stresses that in addition to the diaspora of the Jews, other examples can be traced back to many causes, especially the "ideology" that plays a key role in leaving the homeland. Nevertheless, Pan Yu-liang also relates to the concept of diaspora by Alexander Kitroeff who holds that "remote connection with the homeland with profound affection". She attempted to forge a subjective position of a diasporic female body by means of producing numerous paintings of abundant Chinese images as well as Chinese female body portraits.

In spite of her miserable background and hardships, Pan Yu-liang left behind over four thousand pieces of work including oil paintings, ink paintings, prints, sculptures, drawings and sketches $^{\text {xvii }}$ and in her discovery of arts, she was dedicated to the blending and development of Eastern and Western arts and culture. Using Chinese calligraphic brushstrokes she was good at supplementing with bold blocks of Western colors and she realized the ideal of combining Chinese and Western arts. Her early works were essentially influenced by the West; for instance, in Nude of a Woman Lying on Back (1962), the strong brushstrokes, simple and clear shapes as well as intensive and thick colors reveal a realistic style of the $19^{\text {th }}$ century. Compared with her early works, Portrait of a black woman (1925) shows an elegant style, discreet structure and mature technique, reflecting a discreet painting style of the Western Classism she learned and a longtime academic influence. While evaluating Pan's paintings, Yu Feng used to say: "In her late years, she created ink paintings on Chinese rice paper. It was her innovation to use the ink to form the lines and then

\footnotetext{
xiii Ref.: Fu, Wei-Sin. "Pan Yu-Liang's Achievements in Art". Pan Yu Liang. Taipei: Artist, 2007. 27.

xiv Ref.: Gu, De-Fang. "Interpretation of Pan Yu-Liang's life from her restored oil paintings". Pan Yu Liang. Taipei: Artist, 2007. 21.

xv Ref.: Ke, Meng-De. "Pan Yu-Liang-From Shanghai to Paris School”. Pan Yu Liang. Taipei: Artist, 2007. 15.

xvi Ref.: Gu, De-Fang. "Interpretation of Pan Yu-Liang's life from her restored oil paintings". Pan Yu Liang. Taipei: Artist, 2007. 23.

xvii Ref.: Hu, Sin-Min. “The legendary Chinese woman who merged Chinese and Western painting". Pan Yu Liang. Taipei: Artist, 2007. 7.
} 
incorporate them with kaleidoscopic colors as if decorating the clothes." xviii In terms of Pan's lines and spirit, Chen Du-xiu also gave his insights: "Infusing the dramatic effect of European oil paintings and sculpture into the Chinese line drawing......Her lines are soft, elastic, mild and agreeable, both virtual and realistic. Borrowing the characteristics of Chinese ink paintings, she then expressed the stereoscopy and perspective of Western paintings". (Wei Hong-Chuan 22)

Chow Ching-lie is younger than Pan Yu-liang by almost 50 years. Unlike the diaspora of Pan Yu-liang in the early ROC era, Chow's music creation shares commonality with Pan's portraits. The content meaning, forms, techniques and the multiple cultures interwoven in the transnational migration are the major reasons why Chow's autobiographic text Tears in Paris (in French: Concerto du fleuve Jaune) draw attention among the academic circle. The whole novel features a diasporic woman (the author herself) and depicts her experience of leaving the homeland. She was born in 1936 in war-torn China. At 13 when her father encountered business failure, she was forced to marry someone who was 13 years older than her and had long suffered from a disease. Tortured and humiliated by the in-laws, she later moved from Shanghai to Hong Kong with them. In order to fulfill her dream of becoming a pianist, she had to leave her two children and departed for France to study, and thus began her diaspora in a foreign country. Chow Ching-lie's diaspora can be specified in two periods: The first was escaping from her family where men were superior to women under the patriarchal tradition. The second was leaving her husband and in-laws who made her worn out. Both diasporic experiences arose from the breakaway of patriarchal oppression and the pursuit of liberation by a marginalized woman. At the beginning of the book Tears in Paris, the author describes her struggle and hesitation to let go of her family and homeland. She wrote: "When I think of leaving a 13-year-old boy and an 8-yearold girl, my heart is broken" (Chow Ching-lie 3). However, in the patriarchal society at that time, in order to speak out for themselves, women had to leave to turn around their marginalized conditions through the diasporic experiences in foreign countries where they were reborn with new lives :

"But, I understand, the dramatic difference between a talented amateur artist and a pianist who has to support herself and two children with her arts. Therefore, I want to advance further in music, to become a real artist. In those years, a Chinese artist who studied abroad enjoyed a much better treatment back home. Some artists went to Europe to be "plated with gold" and immediately received a pseudo reputation. But I, I really want to go abroad for advanced study!" (Chow Chinglie 02)

Similar to the diasporic reason for Pan Yu-liang to study abroad in France, Chow Chinglie knew very well that leaving for France was a choice she had to make. In face of the ethical repression and custom hindrance in the traditional society where men are considered superior to women, without inherited property, land and the burden of social status and power, women are more flexible in migration. As Toloyan Kaching said above, women's "diaspora" experience can be transformed into forms such as "study tours", "leaving home", "immigration",

xviii Ref.: Liou, Hai Li. "A Female Artist-Pan Yu-Liang”. Selected Works of Pan Yu Liang. Nanjing: Jiangsu Fine Arts Publishing House, 1988. 10. 
"roaming", "exile" and "traveling". However, through Pan Yu-liang's paintings and Chow Ching-lie's text, given the spiritual and physical repression faced by women, even returning after leaving home, the Chinese women at that time could never escape from the fear, uncertainty and insecurity brought forth by "diaspora"; consequently, they chose to escape or flee again and that was why the two artists eventually chose to live in a foreign land - France. At the end of the text Chow Ching-lie says, "I have announced to all what kind of musician I am. I will always be a daughter of China. Although I live abroad, I still wish to make my home country proud of me, and I will continue working for her" (Chow Ching-lie 238).

\section{Recalling the homeland/the memory}

The majority of the many works of Pan Yu-liang are portraits, among which self-portraits are a category that particularly stands out. "Pan Yu-liang's portraits are infused with Oriental classical beauty, which represents her pursuit and desire for forging herself in the test of life....." (Ke Meng De 88) Her self-portrait is profound in structure, rough in brushstrokes with the figure dressed in a traditional Chinese cheongsam, her hair in a Chinese bun and a calm and stubborn look. Pan used to say: "The self-portraits are the real reflections of Parisian life, revealing the real me in front of the public....... I paint self-portraits as I am always lonely, and I am the person who knows myself best". (Chen Ting 63) Her self-portraits can be considered as a combination of her subject and object. With delicate brushstrokes, she reflected on her inner world; with the portraits, she highlighted her identity as Chinese; and with the Chinese accessories and outfits, she unveiled her Chinese origin. Many of her self-portraits represent her lifestyle of different periods and express her mind and nostalgia for the home country. In Self-portrait in black outfit (1940) (picture 1), Pan Yu-liang is seated in a black cheongsam by the table with her left hand resting on the table and eyes gazing forward. Her pale look strongly contrasts with the bright chrysanthemum beside her; revealed between her locked eyebrows is the artist's nostalgia for her home country. It was painted during the war between China and Japan and being in a foreign country, Pan was deeply concerned about the condition back home and her anxiety and unease could be sensed from her dark outfit. The Self-portrait with a fan (1939) (picture 2) also features the same cold tones, similar S-shaped posture and Chinese cheongsam to the previous portrait. Yet, this painting differs from the previous one as there is a window in the background. The background of her leaning on the window signifies the painter's desire for her home country. The way she looks far toward her home country through the window corresponds with her dark cheongsam, rendering a reflection of her self-image as her creation desire. In contrast with the closed window in the previous painting, in Self-portrait by the window (picture 3) (1945), she kept the window open and painted with bright saturated colors and thick heavy brushstrokes, attempting to get rid of the previous depression and gloominess. Although the work appears to be bright, the dark cherry dress on the painter and her posture and look by the window give it a sad touch. Although she was famous around the globe by then, her nostalgia struck her and her locked eyebrows revealed her reluctant diaspora. In another two paintings Self-portrait in red (picture 4) and Self-portrait with a book (picture 5), she holds a family letter from China and the red Quotations From Chairman Mao Tse-Tung. It is obvious that China was under Mao's rule and that the country was not open to 
others. The painter in France could only maintain contact with her remote family through letters. The images of the letters and the quotations from Chairman Mao Tse-Tung again uncovered the strong nostalgia of the artist. Although she was in a cheongsam, the sentiment released from her depressed eyes showed how the painter was attempting to reflect on her current status and her loneliness and sadness through the record of her living environment.

While many of Pan's self-portraits were painted in different periods and the postures were not identical, in general they face the audience with eyes revealing sadness and lips closed, showing the woman's inner emotion and sentiment for diaspora. Said Edward used to say: "It is in culture that we can seek out the range of meanings and ideas conveyed by the phrases belonging to or in a place, being at home in a place". (Said Edward 8) Regardless of the marginalized identity, a deep nostalgia for home and country, or a sad look back from homeland, these are all common comforts for the minorities or people of diaspora who experience setbacks in foreign cultures, again affirming the inherent and profound affection for the mother culture. For Pan Yu-liang, the painting can be considered as her sense of belonging, the artist's only way to look for memories for the homeland. Past/present, memory/reality, China/France, the interwoven space and time seem to freeze on the canvas, reminding us of the identity issue of the diasporic artist in France who longed for a reunion with family in China. Pan Yu-liang, who chose to live in France due to ideological differences, expressed her profound affection for the homeland in many of her paintings. Through the metaphors of looks and backgrounds, she combined diaspora with dark colors and rested her soul on the canvas.

After experiencing diaspora and life in France, Pan Yu-liang, Chow Ching-lie as well as other Chinese writers/artists who migrate abroad have been looking for a land in which to settle. The diasporic Chinese have difficulty assimilating into the cultural system of the host country, in other words, they have to face the cultural conflicts between their homeland and the foreign land. The author explicitly describes in the book Tears in Paris the embarrassment they encountered when they first arrived in France:

"When I was just about to leave, all of a sudden, she kissed me on my left cheek. I thought to myself happily that it was my good performance that made the teacher kiss me out of satisfaction. I smiled and turned to leave again. But she grabbed me and kissed me again on my right cheek. I was totally confused and hesitated to leave. I turned my left cheek to her again for another kiss. This time she laughed, but since I had approached her, she gave me another kiss and pushed me away. Later, I understood, that this is a courtesy for the French people to greet and say goodbye, usually there are two kisses..." (Chow Ching-lie 17)

The French greeting by kissing cheeks is hard to accept for the conservative Chinese women. In terms of the etiquette of being the guest, the author also encountered the cultural bottleneck: "I think I know what to do. According to the Chinese custom, I should bring over a basket of fruits, several hams or a chicken. (...) When Ms. Yuan opened the door for me and saw me carrying a hen and some fruits, she was so surprised and pleased that I will never forget it. She explained with smiles that in Europe, the guests usually bring fresh flowers, cakes and candy, never do they bring meat." (Chow Ching-lie 19) If we look into the issue from identity theories, the Chinese identity can generally 
be divided in three categories: firstly, emotionally the immigrant still strongly considers herself Chinese; secondly, she identifies with Chinese culture but also accepts the new culture or thirdly, the long-term Chinese immigrant who gradually breaks away from the culture of origin and develops an exclusive cultural identity. After years living in France and going from not identifying to cultural identifying, Chow's identity falls into the second category of "double cultures". However, even her self-identity had changed; her Oriental outlook on the foreign land had made her experience local cultural discrimination. In the book she recalled an experience while returning home from the restaurant: a French woman who was walking a dog fiercely shouted at her: "You yellow people, what on earth are you doing in our country?" At this moment, the author had left her car and was locking it while the woman kept on shouting: "I know why, because your poor country can't afford to support you..." (Chow Ching-lie 138) Another cultural discrimination happened when the author moved a motorcycle illegally parked by a French man in front of her shop. The man reproached her with rage: "I am going to teach you - a Chinese woman - a lesson so that you will never lay your hands on my motorcycle! (...) You are a woman that can't be communicated with reason, you must have been kicked out by your communist party. It has been kind of France to let you stay and you dare to take our place as yours?"(Chow Ching-lie 136) The two experiences of cultural discrimination in the foreign land gave her no choice but to turn to noncultural identification, the repeated diasporic path of leaving and returning.

As we examine the diasporic experiences of Pan Yu-liang and Chow Ching-lie, we see that both of them left the homeland for advanced study because of the ideological differences between them and the society; nevertheless, their self-identification in the foreign land is not identical. While Pan lived in France with deep nostalgia, Chow expressed a cross-national, deterritorialization concept with the piano, which matches with the "flexible citizenship" (Ong Aihwa 750) in diaspora theory proposed by Ong Aihwa. As a long-term Chinese immigrant in France, she recalled the homeland in her memory while in France. Situated in a cross-cultural environment, the flexible citizen who is originally an individual of one culture experiences the impact of double or multiple cultures through moving in and out, and thus constructs a homenation image by combining home-leaving memories and a home-returning imagination. The China/France boundary confines the identity of the diasporic individual who is marginalized and speaks out for the marginalized self through creation. "Diasporas are emblems of transnationalism because they embody the question of borders." (Sudesh Mishra 132) Because of the transnational condition of the Chinese immigrants, their mobility has been extending and in the crashes there forms a heterogeneous identity that belongs to themselves. From the imprint of the home "return" to the concern for the marginalized, the two artists have centered their works on the search for identity.

\section{Representation of self-identity}

Among Pan Yu-liang's portraits, in addition to the self-portraits that embody the nostalgia while living in France, there are also many paintings featuring naked women in which she anchors nostalgia and sentiments in the bodies, creating a prototype of body belonging to a female arts creation. "Due to cultural reasons, naked bodies are a theme hardly seen in Chinese paintings (...) 
However, in Pan's works, she has rendered a special importance to the female body. No matter the production number or painting size, these works can be collected, and they include different attitudes, positions and postures..." (Ke Meng De 17) During the 50s and 60s, Pan created many paintings of female bodies with some naked women and others lightly dressed. Each woman has her posture; brushing and putting on makeup, looking into the mirror, reading, chatting, etc. Combining the fine lines in Chinese paintings and the colors in Western paintings, she depicts women's chubby, naked back and buttocks, leaving behind the traditional image of slim ladies. After 1942, she brought the relief shading background of the oil paintings and the post-impressionist pointillist approach into full play and drew together the pristine, vigorous, serene temperaments from the Chinese folk arts, completely liberating the painting of women from the traditional confinement. In Back of a Woman (1960), Pan first used refined and smooth lines to draw the outline of an elegant, serene, naked woman, then employed light color dots to reveal the structure and texture of human bodies. In the background, she applied a pointillist approach and crossed the short lines to produce gradation, successfully blending Chinese ink spirit with Western reality and texture into her colored ink paintings that present beautiful, spiritual, firm and supple aesthetics. The female bodies in her works break away from the constraints in Chinese culture and are not confined by Western rules, unveiling a strong sense of a woman's consciousness.

In terms of theories on self-identity, Stuart Hall stated that; "Identifications viewed as a whole are in no way a coherent relational system... which are diverse, conflicting and disorderly". (Hall Stuart 4-5) Moreover, he further explained that identification is not purely homogeneous; "...this concept of identity does not signal that stable core of the self, unfolding from beginning to end through all the vicissitudes of history without change." (Hall Stuart 4-5) In other words, diasporic people develop "de-centering" and "partially overlapping" communication networks and connect the crosscultural social groups under the woven multiple "current residence" and "homeland". Their strong self-consciousness and deep loneliness are presented as the anxiety for cultural roots and the painful thinking of identification that advances into a spiritual diaspora. For the diasporic people that can't return home, especially for Pan Yu-liang who attempted to seek self-identity from setbacks such as the loss of historical memory, political trauma, cultural muting and missing the mother tongue, the paintings are usually metaphors of a re-built world, with a memory collage and historical trauma the pillars of the works.

Because of her own experience, Pan Yu-liang strived to release the traditionally repressed female bodies; not only did she draw the desire of the viewer out of the box, she also attempted to reshape female bodies with symbols and signs. "The researchers think Pan's later paintings of female bodies are a kind of sign (...) For her, female bodies are objects like still life, therefore there have been some uncommon human postures in her paintings." (Ke Meng De 110) While expressing female bodies through all types of Chinese female postures in the paintings, she also used them as a sign that interprets the broken memories between her own self and home. The lips, gazes, and repressed expressions can be considered as signs of her nostalgia, but the drawing structure based on the female bodies as objects explicitly shows her attempt to transform the marginalized female bodies in her experience into subjects in discourse. Thus, the "centralization" of Pan's body creation not only renders subjectivity of the female bodies, but also speaks aloud for marginalized women. In her Self-portrait (1963) (picture 6), she boldly exposes her breasts on the 
canvas. Different from other Self-portraits in which she is dressed in a cheongsam, in this painting she was seated with naked breasts and crossed legs, along with wine bottles and cigarettes butts on her right, revealing a bold and unrestrained female. In the painting, she smiles with her hand touching her forehead and her misty eyes looking at the scattered wine bottles, and the smells of the cigarettes and wine diffused in the air. From this scene, we may infer that she was attempting to override the traditional tender and gentle female image; by focusing on the breasts that symbolize women, she truthfully interprets the female bodies that are released from the traditional constraints. No longer portraying the slim and delicate women from the image of beauty, the artist depicts bold and unrestrained women in common daily life in the hope of highlighting the issue of female bodies. Pan's female body paintings liberate traditional women from the constraints in the field of painting, and their use of the extension of bodies has become a means of self-expression, which can be linked to her nostalgia to construct a multiple juxtaposition of cultural female bodies.

For Chow Ching-lie, she realizes cross-cultural identification through music and words. She said; "Of course I would like to go back! I've had enough of a roaming life in a foreign land. At many moments of pain and torture, I always think of my mother country." (Chow Ching-lie 139) "While the overseas Chinese are looked down upon and victimized, their first reaction is to think of their mother country. Like a child who thinks of his mother, the feelings for the mother country for hundreds of thousands of overseas Chinese are not hard to understand" (Chow Ching-lie 138). For Chow, each one of her piano pieces is her place of belonging, the only path for her to seek again memories of the homeland. Thus, the crossed space and time all freeze on the musical notes; in the music emerges the identity issue that although Chow is living in France, she is longing for a return to her Chinese family. "I express my hidden affections to the audience through Yellow River; through that piece, I introduce the excellent Chinese culture to the Western world" (Chow Ching-lie 237).

For Chow, who lives in France to realize the dream of being a professional pianist, the attachment to home is expressed through many piano pieces and the existence of self is interpreted through words and musical notes. By projecting the diasporic mind in music, she "tells" the audience her innermost feelings:

"What should I do to prove my loyalty, my innocence for my home country? (.....) To change the faith of my parents and siblings, I have to explain to my home country the mistake of imposing a "traitor" tag on me and why I have to come to France for advanced study. I have to proof it with my performance. During the "Cultural Revolution", the Yellow River Cantata by Xian Xing-hai was adapted to become my first concerto. Thus, I think of using the piano techniques I learned in France to express the Chinese traditional spirit through the excellent work by Xian Xing-hai and spread it in France. I am going to let out my feelings with music. I want to have an open performance. I am going to hold an open concert, one that is the most spectacular in my life. The only thing I mean is, I love China. I am going to play Chinese music and let all of Paris understand it and love it." (Chow Ching-lie 158)

This paragraph reveals Chow's role in attempting to become a cultural communicator. Through cross-cultural music, she shows her diasporic identity and the identification for her 
home country. While resisting the traditional consciousness, she recalls memories for the home country through Oriental symbols. In France, she played the piece Yellow River that represents China and establishes a self-discourse with the crossed "diaspora" consciousness in France and China in the most "flexible" pattern. In the field of arts that is dominated by men, women are reluctant to be trapped in the social frameworks; thus, they blend in Western techniques and Oriental images with multiple and "flexible" strategies to affirm their values and statuses.

\section{Conclusion}

As the first-generation, Western female painter who used to be a poor girl in an ancient town, a woman in a brothel and a concubine that changed her surname, Pan Yu-liang became a representative female artist in the early $20^{\text {th }}$ century in the midst of the tremendous social changes in China. Due to her background, Pan suffered much criticism in China and although she was fortunate to go abroad, the wars and the discrimination by the society made her roam in the foreign land for years, expressing her nostalgia through self-portraits. Moving between China/France, the diasporic Chow Ching-lie chose to live in Paris in order to study arts. Unlike the nostalgia in Pan's self-portraits, Chow interprets her memories for the homeland with the piano. Drawing on Western playing techniques, she performed the piece Yellow River that represents Chinese culture. The combination of the cultural signs of her home country and the techniques of the foreign land renders a "flexible" double identification. If we compare Chow and Pan, who were repelled so as to live in France, both Chinese female artists living in France interpret their self-identification through another "cross-cultural" perspective. Pan represents female bodies with chubby women in all kinds of postures and Chow reveals affection for the home country with all types of Chinese piano pieces.

In conclusion, both artists Pan Yu-liang and Chow Ching-lie are influenced by Western education. Developing respectively in a different space and time, however, they eventually head towards the same home images. The former combines the advantages of Chinese and Western paintings and infuses with her personal colors to depict the softness and easiness of the reality with vivid lines. The latter plays the music of the Chinese signs with her unique playing techniques to highlight her memories for the home country. Drawing from the diasporic experiences, both Chinese French artists outline their self-identification with the respective art forms and show the self-reflection of diaspora/crossing boundaries. Under the umbrella of Western culture, Pan and Chow certified their "diaspora" identity with cross-cultural, misplaced signs. No matter whether it is Pan Yu-liang under the social diasporic experience, or Chow Ching-lie attempting to be liberated from gender confinement, they unveil themselves with mobile identities and art works that depict self-diaspora and provide an open space for dialogue with the reflecting selves.

\section{Conflict of Interest Statement}

The authors declare no conflicts of interests. 


\section{About the Author}

Wen-Hui Chang is Assistant Professor of Department of Applied Linguistics and Language Studies at Chung Yuan Christian University in Taoyuan, Taiwan. A specialist on Chinese-French Writers and Artists in the modern era, cross-cultural study, and diaspora discourse, she has published "Les images françaises dans la littérature franco-chinoise: En commençant par Ki-tong Tcheng", in Romance Notes, and some papers with high citations.

\section{References}

Aihwa, O, 1999. Flexible Citizenship: The Cultural Logics of Transnationality. London: Duke University.

Alexander, K, 2007. The Transformation of Homeland-Diaspora Relations: the Greek Case in the 19th-20th Centuries. J.M. Fossey ed.. Proceedings of the First International Congress on the Hellenic Diaspora. Amsterdam: Gieben, (2), pp233.

Arnold, A, 1973. The Diaspora Dimension. The Hague: Marinus Nijhoff.

Bell, H, 1990. "Choosing the Margin as a Space of Radical Openness" Yearning: Race, Gender, and Cultural Politics. Boston: South End Press, pp 53-145.

Ching-Lie, C, 2001. Concerto du fleuve Jaune. Paris: Robert Laffont.

De-Fang, G, 2007. "Interpretation of Pan Yu-Liang's life from her restored oil paintings". Pan Yu Liang. Taipei: Artist, pp 20-23.

Dominique, S, 1999. "From the Nation-State to the Transnational World: on the Meaning and Usefulness of Diaspora as a Concept". Diaspora 8 (3), pp225-254.

Edward W, S 1983. The World, the Text, and the Critic. Harvard: Harvard UP.

Hai Li, L, 1988. "A Female Artist-Pan Yu-Liang". Selected Works of Pan Yu Liang. Nanjing: Jiangsu Fine Arts Publishing House.

Hong-Wei, W, 2004. “Chen Du-Xiu and Pan Yu-Liang”. Dangshi Zonglan 2, pp44-46.

John, B, 1972. Ways of Seeing. London: Viking Press.

John, D, 2001. The Poetics of Diaspora. London: Continuum.

Kaching, T, 1996. "Rethinking Diasporas: Stateless Power in the Transnational Moment". Diaspora 5.1, pp3-36.

Kathryn, W, 1997. Identity and Difference. CA: Sage Publications.

Liang-Ya, L, 2001. “The Mother-Daughter Relationship in Maxine Hong Kingston's 'The Woman Warrior'". Chung Wai Literary, pp75-158.

Meng-De, K, 2007. “Pan Yu-Liang-From Shanghai to Paris School”. Pan Yu Liang. Taipei: Artist, pp14-19.

Mishra, S, 2006. Diaspora Criticism. Edinburgh: Edinburgh UP.

Nicholas, M, 2009. An Introduction to Visual Culture. London: Routledge.

Sin-Min, H, 2007. “The legendary Chinese woman who merged Chinese and Western painting”. Pan Yu Liang. Taipei: Artist, pp 6-7.

Stuart, H, 1996. “Introduction: Who Needs identity?" Questions of Cultural Identities. CA: Sage Publications, pp 4-5. 
Ting, C, 2007. "The Research on Pan Yuliang's Figure Painting". Arts Exploration Journal of Guangxi Arts College, pp 63-66.

Virinder S., K, 2005. Diaspora and Hybridity. CA: Sage Publications.

Walter, C, 1986. “The Impact of Homelands Upon Diasporas". Modern Diasporas in International Politics. New York: St. Martins, pp 16-46.

Waltraud, K, Khachig, T \& Carolin, A, et al. 1991. “Diasporas in Modern Societies: Myths of Homeland and Return". Diaspora 1.

Wei-Sin, F, 2007. "Pan Yu-Liang's Achievements in Art". Pan Yu Liang. Taipei: Artist, pp 24-31.

William, S, 2006. "Deconstructing and Comparing Diasporas". Diaspora, Identity and Religion. NY: Routledge, .

Yu-cheng, L \& Kim-Tong, T, 2010. Diaspora and Homeland Imagination: Essays in Literary and Cultural Studies. Taipei: Yun Chen.

Yu-Liang, P, 1995. Pan Yu Liang. Taipei: National Museum of History.

---, 2006. La Peintre :Pan Yu Liang. Taipei: Min Sheng Bao.

---, 2007. Pan Yu Liang. Taipei: Artist. 
Creative Commons licensing terms

Author(s) will retain the copyright of their published articles agreeing that a Creative Commons Attribution 4.0 International License (CC BY 4.0) terms will be applied to their work. Under the terms of this license, no permission is required from the author(s) or publisher for members of the community to copy, distribute, transmit or adapt the article content, providing a proper, prominent and unambiguous attribution to the authors in a manner that makes clear that the materials are being reused under permission of a Creative Commons License. Views, opinions and conclusions expressed in this research article are views, opinions and conclusions of the author(s). and European Journal of Literature, Language and Linguistics Studies shall not be responsible or answerable for any loss, damage or liability caused in relation to/arising out of conflicts of interest, copyright violations and inappropriate or inaccurate use of any kind content related or integrated into the research work. All the published works are meeting the Open Access Publishing requirements and can be freely accessed, shared, modified, distributed and used in educational, commercial and non-commercial purposes under a Creative Commons Attribution 4.0 International License (CC BY 4.0). 